\title{
Severe pulmonary hypertension in Ullrich-Noonan syndrome
}

\author{
ANDREW TINKER, * NEAL UREN, * JOHN SCHOFIELD† \\ From the Departments of ${ }^{\star}$ Clinical Cardiology and $\nmid$ Pathology, Hammersmith Hospital, London
}

SUMMARY A 19 year old woman with Ullrich-Noonan syndrome presented with a six month history of progressive dyspnoea and cyanosis. Clinical features were suggestive of severe o pulmonary hypertension. Cross sectional echocardiography showed pronounced right ventricular pressure overload with right ventricular hypertrophy. Cardiac catheterisation confirmed severe $₫$ pulmonary hypertension. Attempts to reduce pulmonary artery pressure with calcium channel $\cong$ blockers were unsuccessful. The patient died shortly after investigation. Necropsy confirmed primary pulmonary hypertension.

The Ullrich-Noonan syndrome is an autosomal dominant condition of both sexes in which the affected individuals have many of the phenotypic features of Turner's syndrome, but with a normal karyotype and normal secondary sexual characteristics. There is a predisposition to cardiac anomalies, the most commonly described being pulmonary valve stenosis (often associated with an atrial septal defect) and asymmetrical septal hypertrophy. ${ }^{1-3}$ We report a case of severe primary pulmonary hypertension occurring in association with this syndrome and describe the clinical features and pathological findings of a plexogenic arteriopathy.

\section{Case report}

A 19 year old woman was admitted to hospital with a six month history of progressive dyspnoea on exertion. Ullrich-Noonan syndrome was diagnosed when she was two years old and since infancy her exercise tolerance had been reduced by dyspnoea. In the six months before presentation she could only walk 200 metres. This limitation was associated with central cyanosis and a tight central chest pain which resolved on resting. There was no history of syncope. She was also profoundly deaf, but of normal intelligence. Both parents were also profoundly deaf, and her father had the Ullrich-Noonan syndrome. She also had a 17 year old sister with the same syndrome, but with normal hearing, in whom pulmonary stenosis was diagnosed at four months.

Requests for reprints to Dr Neal Uren, Department of Clinical Cardiology, Hammersmith Hospital, Du Cane Road, London W12 0HS.
She was short with mild neck webbing, hypertelorism, bilateral ptosis, cubitus valgus, and widely spaced nipples. She had normal secondary sexual characteristics. There was mild central cyanosis but she was not dyspnoeic at rest. She had a small volume regular pulse and blood pressure of $130 / 70 \mathrm{~mm} \mathrm{Hg}$ in all limbs. The jugular venous pulse was not elevated. There was a prominent right ventricular heave. There was a loud pulmonary component of a narrowly split second heart sound. Examination of the chest was clear, with no peripheral murmurs.

Haemoglobin was $169 \mathrm{~g} / \mathrm{l}$. The chromosomal karyotype was normal. The electrocardiogram showed right axis deviation and right ventricular hypertrophy. The chest radiograph confirmed a normal cardiac diameter with normal lung fields. Cross sectional echocardiography showed hypertrophy of a small right ventricle and bulging of the septum into the left ventricle during systole and diastole consistent with a considerable right ventricular pressure overload (fig 1). There was mild ơ tricuspid incompetence on colour flow Doppler $N$ ultrasound. The pulmonary artery and its branches and the pulmonary valve were normal. The right $O$ atrium was not enlarged. The left heart chambers and valves were normal. The interatrial and interventricular septa seemed to be intact.

Angiography showed a small interatrial communication but no ventricular septal defect or ductus arteriosus. The left ventriculogram was normal. Tables 1 and 2 show basal haemodynamic data $\frac{\mathbb{D}}{Q}$ and oxygen saturations. The patient was given $60 \%$ oxygen over five minutes with continuous measurement of pulmonary artery and aortic pres- $\frac{8}{8}$ 


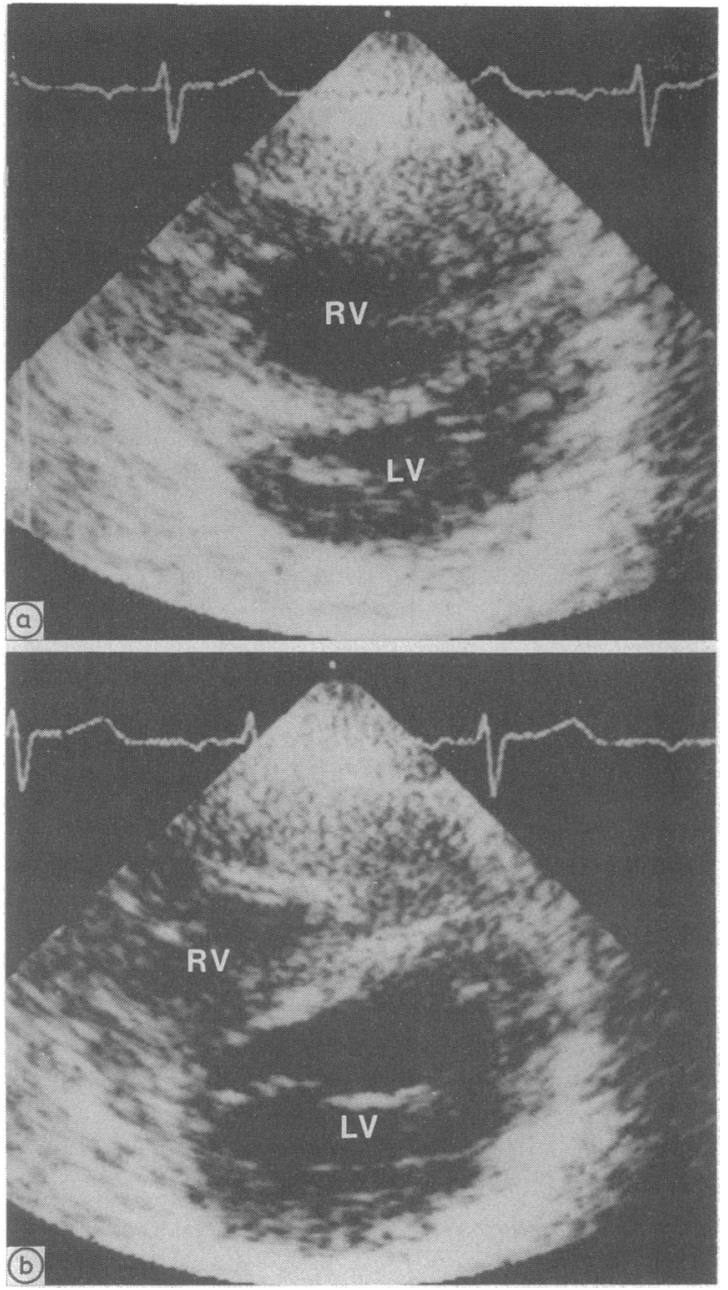

Fig 1 Cross sectional echocardiogram in the short axis showing (a) compression of the left ventricular cavity by the hypertrophied right ventricle in late systole and (b)

flattening of the interventricular septum in late diastole.

sures (tables 1 and 2). The pulmonary artery catheter was left in place and the patient was given anticoagulants. A trial of hourly oral calcium channel blockers was begun, but nicardipine (three doses of $20 \mathrm{mg}$ ), diltiazem ( 12 doses of $60 \mathrm{mg}$ ), and nifedipine (four doses of $20 \mathrm{mg}$ ) did not lower the pulmonary artery pressure.

She died suddenly two weeks later. At necropsy, gross right ventricular hypertrophy and anatomical changes of pulmonary hypertension were confirmed. The interatrial septum was thinned, and two slitlike defects were found $(1.1 \times 0.3 \mathrm{~cm}$ and $0.9 \times 0.2 \mathrm{~cm}$ ) in a poorly displayed fossa ovalis. There was no evidence of sepsis, peripheral pulmon-
Table 1 Dynamic pressure and saturation measurements during cardiac catheterisation

\begin{tabular}{|c|c|c|c|c|}
\hline \multirow[b]{2}{*}{ Site } & \multicolumn{2}{|l|}{ At rest } & \multicolumn{2}{|c|}{$60 \% \mathrm{O}_{2}(5 \mathrm{~min})$} \\
\hline & $\begin{array}{l}\text { Pressure } \\
(\mathbf{m m} \mathbf{H g})\end{array}$ & $\begin{array}{l}\text { Saturation } \\
(\%)\end{array}$ & $\begin{array}{l}\text { Pressure } \\
(\mathbf{m m ~} \mathbf{H g})\end{array}$ & $\begin{array}{l}\text { Saturation } \\
(\%)\end{array}$ \\
\hline $\begin{array}{l}\text { Right atrium } \\
\text { Right ventricle } \\
\text { Main pulmonary }\end{array}$ & $\begin{array}{c}\overline{5} \\
140 / 8\end{array}$ & $\begin{array}{l}68 \\
68\end{array}$ & $\begin{array}{c}\overline{6} \\
140 / 8\end{array}$ & 74 \\
\hline $\begin{array}{l}\text { artery } \\
\text { Left pulmonary }\end{array}$ & $140 / 50, \overline{80}$ & 68 & $140 / 50, \overline{80}$ & 72 \\
\hline $\begin{array}{l}\text { veins } \\
\text { Left atrium } \\
\text { Left ventricle } \\
\text { Aorta }\end{array}$ & $\begin{array}{c}\overline{5} \\
120 / 8 \\
120 / 80, \overline{95}\end{array}$ & $\begin{array}{r}100 \\
93 \\
90 \\
88\end{array}$ & $\begin{array}{l}\overline{110 / 8} \\
110 / 80, \overline{80}\end{array}$ & $\frac{100}{98}$ \\
\hline
\end{tabular}

$\overline{\mathbf{x}}$, mean pressure.

ary stenosis, or thromboembolic disease. Sections of the lung showed extensive diffuse thickening of the arteriolar walls with medial hypertrophy of the immediate precapillary vessels. Most vessels showed intimal proliferation (fig 2a). There were numerous angiomatoid and plexiform lesions in all areas (fig 2b). Fibrinoid necrosis was seen focally in the plexiform lesions. These features suggested severe pulmonary hypertension of histological grade 4 on the Heath and Edwards classification. ${ }^{4}$

\section{Discussion}

The commonest cause of pulmonary hypertension in children and young adults is an intracardiac shunt. It has been suggested that pulmonary hypertension occurs in up to $15 \%$ of patients with atrial septal defects, ${ }^{5}$ but is rare before the third decade. ${ }^{67}$ Primary pulmonary hypertension is a rare disease that usually occurs in young women (aged 15-40). ${ }^{89}$

We believe that the severe pulmonary hypertension described in this patient is likely to be of the

Table 2 Estimated arterial blood flows and calculated vascular resistances

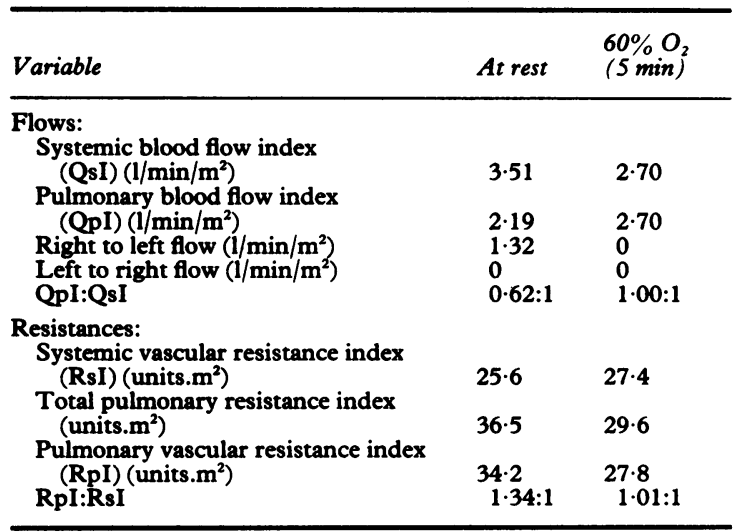



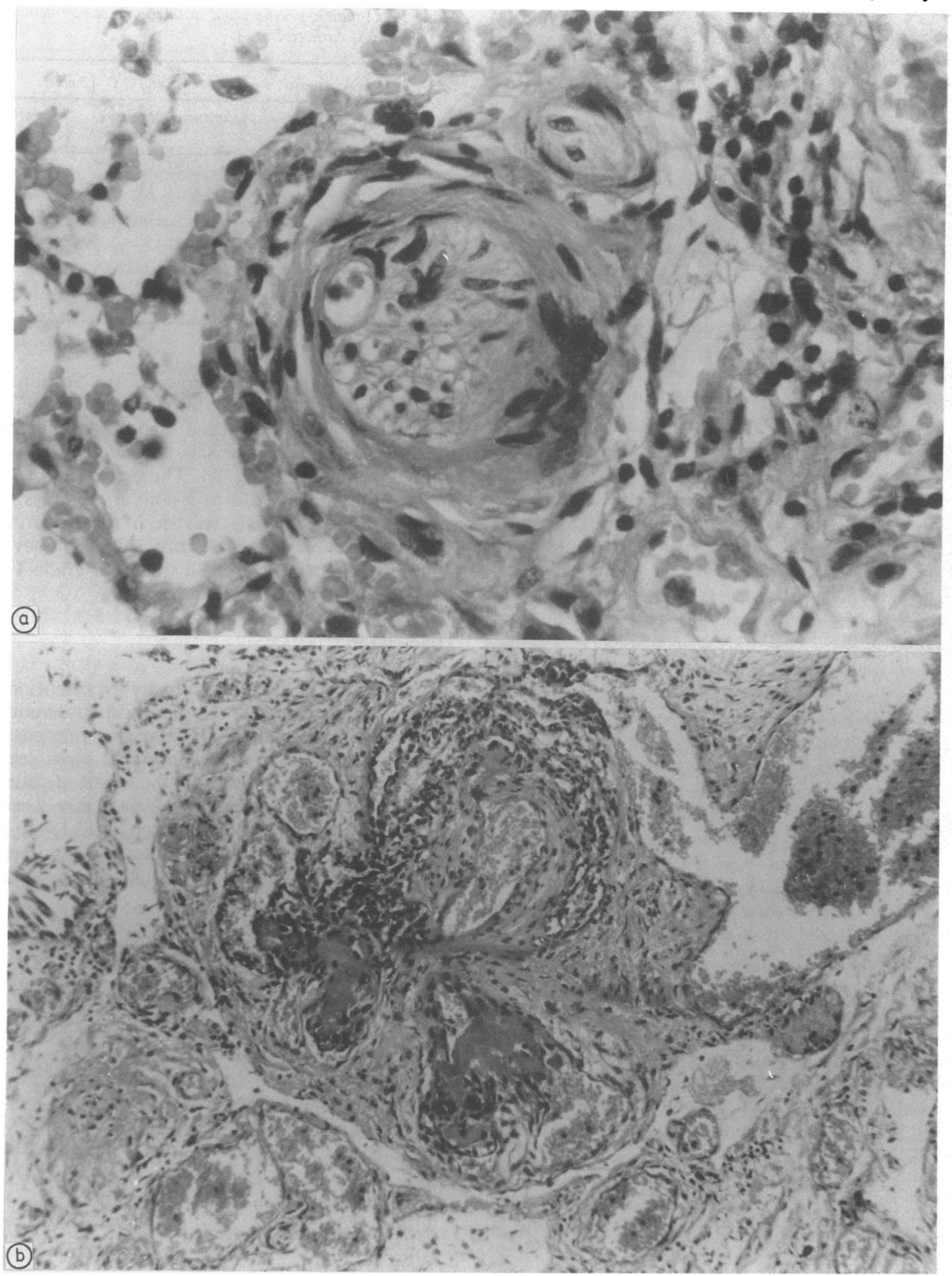

Fig 2 (a) Pulmonary arteriole showing intimal proliferation and medial thickening (haematoxylin and eosin; original magnification, $\times 400$ ). (b) Angiomatoid lesion showing fibrinoid necrosis (haematoxylin and eosin; original magnification, $\times 200$ ). 
primary type. The small atrial septal defects seem to be insignificant in view of hypertrophied, but not dilated, right ventricle and normally sized right atrium, which would exclude a previous large pretricuspid shunt. ${ }^{10}$ Pulmonary hypertension secondary to atrial septal defects is associated with cardiomegaly (cardiothoracic ratio $>0.6$ ) in both older, ${ }^{11}$ and younger patients. ${ }^{7}$ In this case, the cardiothoracic ratio was $<0.5$. There has been only one reported case of the Eisenmenger syndrome in association with an atrial septal defect at this age. ${ }^{6}$ Other features supporting primary type hypertension are the rapid clinical deterioration and the very high pulmonary artery pressure and pulmonary vascular resistance. In addition, the presence and widespread distribution of dilated plexiform and angiomatoid lesions suggest a primary defect. ${ }^{12-14}$

The treatment of severe pulmonary hypertension is unsatisfactory, in the absence of a remediable cause. Because of the unproven hypothesis that vasoconstriction is important in the pathophysiology of primary pulmonary hypertension, vasodilating agents have been used as treatment, with disappointing results. ${ }^{15} \mathrm{~A}$ recent short term improvement, however, was achieved in pulmonary artery haemodynamic function with regression of right ventricular hypertrophy with calcium channel blockers. ${ }^{1617}$ Though the patient reported here showed partial reversibility of the pulmonary vascular resistance during administration of high flow oxygen (table 2), the calcium channel blockers did not affect pulmonary artery pressure or pulmonary vascular resistance.

The small atrial communication does not seem to be relevant to the pulmonary hypertension. The clinical and pathological features suggest the development of primary pulmonary hypertension in this patient with the Ullrich-Noonan syndrome. This association has not been previously described.

We thank Dr Celia M Oakley for advice and Dr Graham J Davies for permission to publish this case.

\section{References}

1 Nora J, Nora A, Sinha AK, Spangler RD, Lubs HA. The Ullrich-Noonan syndrome. Am J Dis Child
1974;127:48-55.

2 Noonan JA, Ehmke DA. Associated non-cardiac malformations in children with congenital heari diseases. $J$ Pediatr 1963;63:468-70.

3 Nora JJ, Torres FG, Sinha AK, Macnamara DG. Characteristic cardiovascular anomalies of XO Turner syndrome, $\mathrm{XX}$ and $\mathrm{XY}$ phenotype, and $\mathrm{XO} / \mathrm{XX}$ Turner mosaic. Am J Cardiol 1970;25:639-41.

4 Heath D, Edwards JE. The pathology of hypertensive pulmonary vascular disease. A description of six grades of structural changes with special reference to congenital cardiac septal defect. Circulation 1958; 18:533-47.

5 Craig RJ, Selzer A. Natural history and prognosis of atrial septal defect. Circulation 1968;37:805-15.

6 Haworth SG. Pulmonary vascular disease in secundum atrial septal defect. Am J Cardiol 1983;51:265-72.

7 Evans JR, Rowe RD, Keith JD. The clinical diagnosis of atrial septal defect in children. Am J Med $1961 ; 30: 345-56$.

8 Harris P, Heath D. The human pulmonary circulation. 3rd ed. Edinburgh: Churchill Livingstone, 1986: 414-32.

9 Fuster V, Steele TM, Edwards WD, Gersh BJ, McGoon MD, Frye RL. Primary pulmonary hypertension: natural history and the importance of thrombosis. Circulation 1984;70:580-7.

10 Wood P. Diseases of the heart and circulation. 3rd ed. London: Eyre and Spottiswoode, 1968:419-34.

11 Markham P, Howitt G, Wade EG. Atrial septal defect in the middle-aged and elderly. $Q J$ Med 1965; 34:409-26.

12 Haworth SG. Primary pulmonary hypertension. $\mathrm{Br}$ Heart J 1983;49:517-21.

13 Wagenvoort CA, Wagenvoort N. Primary pulmonary hypertension: a pathologic study of the lung vessels in 156 clinically diagnosed cases. Circulation 1970; 42:1163-84.

14 Spencer H. Pathology of the lung. 4th ed. Oxford: Pergamon Press, 1985:631-704.

15 Packer M. Vasodilator therapy for primary pulmonary hypertension. Ann Intern Med 1985;103:258-70.

16 Rich S, Brundage BH. High dose calcium channelblocking for primary pulmonary hypertension: evidence for long term reduction in pulmonary arterial pressure and regression of right ventricular hypertrophy. Circulation 1987;76:135-41.

17 Rich S, Brundage BH, Levy PS. The effect of vasodilator on the clinical outcome of patients with primary pulmonary hypertension. Circulation 1985; 71:1191-6. 